\title{
Determination of the Polyphenolic Content of Dorycnium herbaceum Plant Extract and Testing in vivo Antioxidant Effect, Comparative with Bilberry
}

\author{
OANA NICOLAESCU*, RENATA-MARIA VARUT, STEFANIA PATRUNA \\ University of Medicine and Pharmacy of Craiova, Pharmacy, 2-4 Petru Rares Str., 200349, Craiova, Romania
}

\begin{abstract}
Dorycnium herbaceum (DH) is a perennial herb or small shrub $10-80 \mathrm{~cm}$ high, which can be found in Central and Southeastern Europe. It is a little studied plant, which is known to have antibacterial and antifungal effect. In the presentstudy we determined by spectrophotometric methods the total polyphenolic, flavonoidic, carotenic and chlorophyllic content of DH species, comparative to the bilberry. We also monitored the status of antioxidant enzymes using mice with oxidative stress induced by streptozotocinic diabet. For the induction of diabetes we used Swiss albino mice to which we injected streptozotocin intraperitoneally at a single dose of $180 \mathrm{mg} / \mathrm{kg}$ b.w.. The results showed that both chemical composition tinctures contain appreciable amounts of polyphenols, the highest content starring DH tincture species, but bilberry fruits have higher content of flavonoids, carotene and chlorophyll. Both plant extracts regulate the status of antioxidant enzymes, DH having superior efficacy.
\end{abstract}

Keywords: Dorycnium herbaceum, bilberry fruits, streptozotocinic diabet, antioxidants

Polyphenols are plant secondary metabolites having antioxidant properties, which help to protect against chronic diseases made by free radical damage. Polyphenols can be often found in fruits, vegetables, tea, coffee, chocolates, legumes, cereals and beverages [1]. Polyphenols are divided into four different categories based on the presence of number of phenolic groups and structural elements: flavonoids, stilbenes, lignans, phenolic acid [23]. Inside human body polyphenols act like antioxidants [4], antidiabetic, anticancer, antiinflammatory, cardioprotective, osteoprotective, neuroprotective, antiasthmatic, antihypertensive, antiageing, antiseptic, cerebrovascular protection, cholesterol lowering, hepatoprotective, antifungal, antibacterial and antiviral agents [5].

Dorycnium herbaceum (Fabaceae) is a perennial herb or small shrub $10-80 \mathrm{~cm}$ high, which can be found in Central and Southeastern Europe. DH is a little studied plant known to have antibacterial effect (Bacillus subtilis, Staphylococcus aureus, Pseudomonas aeruginosa and Proteus mirabilis) and antifungal (Candida albicans, $C$. albicans, Aspergillus niger, Penicillium italicum, Penicillium digitatum, Penicillium verrucosum) [6]. DH contains phenylbutanone glucosides, flavonoids, cyanogenic glucoside, cyclitol and hydroquinone glucoside, the chemical composition being determined by using spectrometric methods [7]. The major constituent of the methanolic extract is miricetrin. It also contains phytoestrogens (isoflavonoids, cumestans and lignans), being the first time when phenylbutanone derivatives have been isolated in plant species of the Fabaceae family [8]. Also contains chlorogenic acid, chlorophylls, in traces apigenol-7-glucoside flavonoside and rutin, volatile compounds (acid ethyl ester ethanimidic, 2-propen-1-ol acetate, 1.1 diethoxy ethane) [9]. Antioxidant, hypoglycemic or hypolipidemic potency testing is often performed using animal models, most commonly mice or rats with experimentally induced streptozotocinic diabetes [10].
In the present study we determined the polyphenolic content of Dorycnium herbaceum herba extract (DH-h), and tested the antioxidant effect using mice with streptozotocin diabetes. We tested it comparative to Vaccinium myrtillus folium (VM-f), recognized for its antioxidant properties [11]. VM-f contains phenolic components: chlorogenic acid, apigenol rutoside, chlorophylls and volatile component (ethyl-methyl carbonate), identified by TLC, HPLC, GC-MS analysis [12]. Dietary polyphenols can have important beneficial effects on human health.

\section{Experimental part \\ Material and method \\ Plant material}

The plants of DH were harvested from the Botanical Garden of Craiova City (Dolj County, Romania) between May and J une. Leaves were air-dried in the shade at room temperature. The samples of VM-f were purchased as fresh fruits from supermarket. Herbarium voucher samples are deposited in the Laboratory of Pharmacognosy (Faculty of Pharmacy, University of Medicine and Pharmacy of Craiova, Romania).

Sample preparation

Vegetable products were used as hydroalcoholic extracts manufactured by simple leaching at dry plant material/solvent ( $70 \%$ aqueous ethanol) ratio of $1: 5$ according to FRX [13]. A control sample of the extract can be found in the collection of the Laboratory of Pharmacognosy, Craiova [13].

\section{Chemical Analysis of Extracts}

Determination of total phenolic content (TPC)

We used Folin-Ciocalteu reagent using gallic acid (GA) as a standard for calibration. Using an Able-J asco V530 UV/Vis spectrophotometer we measured the absorbance at $765 \mathrm{~nm}$ with. Determinations were carried out in triplicate, averaged, and calculated from the calibration curve with concentrations of GA ranging from 0 to 1500 
$\mathrm{mg} / \mathrm{L}$. The results were expressed in gallic acid equivalents (g GAE)/L of extract.

Determination of flavonoids content (FC)

We determined $\mathrm{FC}$ colorimetrically using aluminum chloride. The absorbance was measured at $415 \mathrm{~nm}$ with an Able-Jasco V530 UV/Vis spectrophotometer. Determinations were carried out in triplicate, averaged and calculated from the calibration curve constructed with quercetol ( $Q E)$ as a reference, with concentrations ranging from 0 to $200 \mathrm{mg} / \mathrm{L}$.

Determination of total carotenoids and chlorophylls a and $b$

Hydroalcoholic solutions of plant extracts of the appropriate concentration ( 1.0 to $4.0 \mathrm{mg} / \mathrm{mL}$ ) were analyzed in a UV/Vis spectrophotometer at 470,653 and $666 \mathrm{~nm}$. The concentrations of carotenoids and chlorophylls $\mathrm{a}$ and $\mathrm{b}$ were calculated using the following formulas:

Total carotenoids $(\mathrm{mg} / \mathrm{L})=1000$ Abs470 $-2.860 \mathrm{Ca}-$ $129.2 \mathrm{Cb} / 245$;

Chlorophyll a $(\mathrm{mg} / \mathrm{L})=15.65$ Abs666 - 7.340 Abs653; [14]

Chlorophyll $b(\mathrm{mg} / \mathrm{L})=27.05$ Abs653 -11.21 Abs666.

\section{Study design}

Experiments were conducted on adult Swiss albino mice distributed in four groups:

Group I: mice with normal pancreatic function (C);

Group II: diabetic mice (D);

Group III: diabetic mice treated with $\mathrm{DH}-\mathrm{h}$ extract at $200 \mathrm{mg} / \mathrm{kg}$ b.w. (5.25 -6.75 mg extract dissolved in $0.3 \mathrm{~mL}$ distilled water);

Group IV: diabetic mice treated with VM-f extract at 150 $\mathrm{mg} / \mathrm{kg} \mathrm{b.w} \mathrm{(5.25} \mathrm{-6.75} \mathrm{mg} \mathrm{extract} \mathrm{dissolved} \mathrm{in} 0.3 \mathrm{~mL}$ distilled water), a plant product recognized for its antioxidant effect.

Protocol for the induction of diabetes mellitus

To obtain diabetic mice we used healthy male Swiss albino mice aged 6 - 8 weeks, weighing within $35-45 \mathrm{~g}$ (from Animal Husbandry of the University of Medicine and Pharmacy of Craiova). The animals were kept fasting $12 \mathrm{~h}$ before the intraperitoneal single dose (180 mg/kg b.w) injection. After the administration of streptozotocin, in order to avoid hypoglycemia animals had access to a solution of glucose $(5 \%)$ for $24 \mathrm{~h}$. The animal weight and blood glucose level were monitored before streptozotocin injection, $72 \mathrm{~h}$ after injection, and in one week after treatment, the animals being kept fasting for $12 \mathrm{~h}$ before blood sampling for biochemical determinations. Animals with fasting blood glucose over $300 \mathrm{mg} / \mathrm{dL}$, confirmed by two measurements were considered diabetic and were distributed in test groups. The glycemia was measured with eBsensor glucometer taking blood from the tail vein. The protocol of the study was approved by the Ethical and Scientific Commissions of the University of Medicine and Pharmacy of Craiova [15].

\section{Blood and tissue sampling}

After five weeks of testing animals were sacrificed; blood samples were collected in heparinized tubes, processed for plasma separation and erythrocytes hemolysis to determine the level of lipid peroxides and the activities of enzymes: superoxide dismutase (SOD), glutathione peroxidase (GPx) and glutathione reductase (GR).

\section{Determination of oxidative stress biomarkers}

In order to determine the oxidative stress status we followed the recommendation from the inserts of commercially available kits purchased from Randox Labs. (United Kingdom).

\section{Erythrocyte hemolysis}

Sample $(0.5 \mathrm{~mL})$ of whole blood was centrifuged for 10 min at $3000 \mathrm{rpm}$, plasma was discarded, and the cells were washed four times with physiological saline solution and centrifuged for $10 \mathrm{~min}$ at $3000 \mathrm{rpm}$ after each wash. Washed erythrocytes were made up to $2 \mathrm{~mL}$ with cold redistilled water, mixed, and kept for $15 \mathrm{~min}$ at $4^{\circ} \mathrm{C}$. When used to assess enzyme activity, the lysate was diluted with $0.01 \mathrm{M}$ phosphate buffer solution $\mathrm{pH} 7$.

Determination of superoxide dismutase (SOD) activity

The SOD activity in erythrocytes was measured by the rate of inhibition of 2-(4-iodophenyl)-3-(4-nitrophenol)-5phenyltetrazolium (INT) transformation by the superoxide generated from the reaction catalyzed by xanthine oxidase (RanSOD kit). The SOD activity expressed in units (UI) is defined as the amount which inhibits by $50 \%$ the rate of INT transformation at $37^{\circ} \mathrm{C}$.

Determination of glutathione peroxidase (GPx) activity

The GPx activity in erythrocytes was measured from the variation of absorbance at $340 \mathrm{~nm}$ following the oxidation of GSH by cumene hydroperoxide and the reduction of GSSG with GR and NADPH, H+ (Ransel kit).

Determination of glutathione reductase (GR) activity

The GR activity was measured from the decrease in absorbance at $340 \mathrm{~nm}$ after the oxidation of NADPH, $\mathrm{H}+$ when GSSG is reduced to GSH (Randox Glut Red kit).

Determination of thiobarbituric acid reactive species (TBARS) level

Malondialdehyde (MDA), marker of lipid peroxidation, was estimated as TBARS using a solution of thiobarbituric acid in 20\% tricholoroacetic acid. The absorbance at 535 $\mathrm{nm}$ was measured and the results, expressed as $\mathrm{mmol}$ $M D A / L$, were calculated using the extinction coefficient of MDA.

All measurements of oxidative stress biomarkers were carried out using a Beckman UV-Vis DU-65 spectrophotometer equipped with a temperature control module (Beckman Instruments, Fullerton, United States). All experimental measurements were carried out in triplicate and are expressed as average of three analyses \pm standard deviation [16].

\section{Results and discussions}

The antioxidant nature of phenolic acids is due to the presence of hydroxyl groups, which participate in the redox reaction, neutralizing free radicals such as peroxo, oxo, hydroxo. The determinations showed that both tinctures contained appreciable amounts of polyphenols, the highest content being found in VM-f tincture $(0.732 \pm 0.177 \mathrm{~g} \mathrm{GAE}$ / ( table 1)). From the flavonoid content point of view, the richest tincture is VM-f $(0.7909 \pm 0.020 \mathrm{gQE} / \mathrm{I})$. Also, VMf has carotenic and chlorophyllic content higher than $\mathrm{DH}$ h.

The reference antioxidant product is the hydroalcoholic extract of bilberry, traditionally used as antioxidant, antiinflammatory, antidiabetic and hypolipidemic $[17,18]$.

In diabetes there are several ways of producing oxidative stress: nonenzymatic, enzymatic, and mitochondrial.

Non-enzymatic sources of oxidative stress come from oxidative biochemistry of glucose. Prolonged hyperglycemia can directly cause reactive oxygen species (ROS) generated in several stages. The enzymatic sources for generating reactive oxygen species in diabetes include NOS, NAD (P) H oxidase and xanthine oxidase [19]. The mitochondrial respiratory chain is another non-enzymatic source of reactive species. -02 mitochondrial is the initiator that transforms oxidative stress into an avalanche by stimulating ROS and RNS formation, mediated 


\begin{tabular}{|l|l|l|l|l|l|}
\hline Tinctura & Total fenolic & $\begin{array}{c}\text { Total flavonoidic } \\
{[\mathrm{g} \mathrm{QE} / \mathrm{L}]}\end{array}$ & Carotenoide \\
{$[\mathrm{g} / \mathrm{L}]$} & Clorofila $a[\mathrm{~g} / \mathrm{l}]$ & Clorofila $b[\mathrm{~g} / \mathrm{l}]$ \\
\hline $\mathrm{DPH}$ & $0.732 \pm 0.177$ & $0.495 \pm 0.011$ & 2.142777966 & 0.010134 & 0.0156231 \\
\hline VM-f & $0.6334 \pm 0.025$ & $0.7909 \pm 0.020$ & 4.8821 & 0.0282 & 0.0711 \\
\hline
\end{tabular}

Table 1

Tabelul 2

MEAN LEVELS OF OXIDATIVE STRESS BIOMARKERS IN BLOOD (MEAN \pm SD)

\begin{tabular}{|l|l|l|l|l|}
\hline Group & GR (U/), & GPx (U/) & SOD (U/ml) & POL ( mmoli MDA/) \\
\hline Group I & $60.25 \pm 1,91$ & & & \\
\hline Group II & $46.3 \pm 2.12$ & $4251.5 \pm 28.99$ & $203,8 \pm 1.84$ & $0.5350 \pm 0.06$ \\
\hline Group III & $61.4 \pm 2.26$ & $6269 \pm 207.89$ & $220.3 \pm 0$ & $0.9594 \pm 0.014$ \\
\hline Group IV & $51.5 \pm 0.50$ & $4200 \pm 18.5$ & $190.2 \pm 10.6$ & $0.6602 \pm 0.045$ \\
\hline
\end{tabular}

production of NF- $\mathrm{KB}, \mathrm{PKC}$ and NAD (P) H oxidase mediated cytokines [20].

Glutathione reductase is also an enzyme that reduces glutathione disulfide (GSSG) to form GSH sulfhydryl, an important cellular antioxidant. GR is a homodimer found in both cytosol and mitochondria. For each mole of oxidized glutathione (GSSG), one mole of NADPH is required to reduce GSSG to GSH [21]. The plasma level of glutathione reductase is low in the presence of diabetes mellitus and oxidative stress [22]. At the end of the experiment, untreated diabetic group II had the lowest mean glutathione reductase $46.3 \pm 2.12 \mathrm{U} / \mathrm{mL}$. VM-f tincture has antioxidant properties noted by the mean glutathione reductase enzyme of $51.5 \pm 0.50 \mathrm{U} / \mathrm{mL}$, higher than that of group II, $46.3 \pm 2.12 \mathrm{U} / \mathrm{mL}$.

Glutathione peroxidase, a selenium-dependentenzyme, catalyzes the degradation of organic hydroperoxides formed by metabolic processes, using glutathione as electron donor. Glutathione peroxidase is located in the cytosol and mitochondria and protects the structure of proteins, lipids and nucleic acids of the reactive species of oxygen [23]. The plasma level of glutathione peroxidase is low in the presence of diabetes mellitus and oxidative stress. At the end of the experiment, untreated diabetic group II had the lowest mean glutathione peroxidase value (3415.5 $\pm 98.29 \mathrm{U} / \mathrm{L}$ ). VM-f tincture has antioxidant properties, resulting from the comparison of the average value of the glutathione peroxidase of the group IV treated with it (4 $200 \pm 18.5 \mathrm{U} / \mathrm{L}$ ), with the average values of the group II (3415.5 $\pm 98.29 \mathrm{U} / \mathrm{L}$ ) and group I ( $4251.5 \pm 28.99$ $U / L)$.

Superoxide dismutase (SOD) is an antioxidant enzyme that catalyzes the dismutation of superoxide anion in hydrogen peroxide and molecular oxygen. SOD has a protective role against cellular and histological changes produced by ROS. Supplements containing antioxidants, including SOD-mimetics, reduce ROS concentration, and increase the level of antioxidant enzymes, being effective in preventing diabetes. At the end of the experiment, diabetic group II exhibited the lowest average value of superoxide dismutase $(191.7 \pm 10.75 \mathrm{U} / \mathrm{mL})$. The antioxidant potential of tinctures results from the mean SOD plasma level, the therapeutic efficacy of DP-h tincture $(220.3 \pm 0 \mathrm{U} / \mathrm{mL}$ ) being superior to the tincture VM-f $(190.2 \pm 10.6 \mathrm{U} / \mathrm{mL})$.

Hydroperoxides may have toxic effects on cells both directly and indirectly by degradation of highly toxic hydroxyl radicals. They can also react with transition metals (iron, copper) to form stable aldehydes, such as malondialdehyde (MDA), which affects the structure of cell membranes. In diabetes, significantly higher levels of thiobarbituric acid (TBARS) reactive substances were observed in red blood cells as well as in serum and decreased antioxidant enzyme activity. Recent clinical studies have shown a correlation betw een increased lipid peroxidation, hyperglycemia, HbAlc level, and oxidative stress in diabetes. The untreated diabetic group II has the highest lipid peroxide values $(2.6937 \pm 0.007 \mathrm{mmol} / \mathrm{L})$. Concerning the limitation of the formation of lipid peroxides in the diabetes mellitus, VM-f is more effective $(0.6602 \pm$ $0.045 \mathrm{mmol} / \mathrm{L})$ than DP-h test tincture $(0.9594 \pm 0.014$ $\mathrm{mmol} / \mathrm{L}$.

\section{Conclusions}

Following the study, we can see that the high level of glucose, sustained for a long time, induces oxidative stress, reflected by increased malondialdehyde concentration and low antioxidant enzymes.

The determinations showed that both tinctures contained appreciable amounts of polyphenols, the highest content being found in VM-f tincture $(0.732 \pm 0.177 \mathrm{~g} \mathrm{GAE}$ $(\mathrm{L})$. From the flavonoid content point of view, the richest tincture is VM-f $(0.7909 \pm 0.020 \mathrm{~g} Q \mathrm{QE} / \mathrm{L})$. Also, VM-f has carotenic and chlorophyllic content higher than DH-h.

The analysis of the antioxidant enzymes level show the superior efficacy of the DP-h extract compared to VM-f. Considering that the test tinctures contain flavonoids and polyphenolcarboxylic acids with antioxidant effect, these extractives could be recommended as natural sources of polyphenolic compounds with adjuvant role in the prophylaxis and treatment of diseases caused by the presence of reactive oxygen species in the body. 


\section{References}

1. PANDEY, K.P., RIZVI, S.I., Plant polyphenols as dietary antioxidants in human health and disease, Oxid Med Cell Longev., 2, nr. 5, 2009, p: 270-278.

2.VARUT, R.M., ROTARU, L.T., VARUT, M.C., QSPR Correlation of Physico-chemical Descriptors with the Molecular Surface Area and Rf of Ten Polyphenolic Compounds, Separated from Vegetal Extracts by TLC, Rev. Chim. (Bucharest), 68, no. 8, 2017, p. 1776-1779.

3 BUBULICA, M.V., CHIRIGIU, L., POPESCU, M., SIMIONESCU, A., ANOAICA, G., POPESCU, A., Analysis of sterol compounds from Sambucus ebulus, CHEMISTRY OF NATURAL COMPOUNDS, J uly 2012, Volume 48, Issue 3, pp 520-521

4 BUBULICA, M.V., CHIRIGIU, L., Screening of antioxidant potential of Lonicera tatarica, Viburnum opulus and Sambucus ebulus L. by multiple in vitro assays, J OURNAL OF MEDICINAL PLANTS RESEARCH, 6(3), 544-552

5.KUMAR, G., BAOJUN, X., A Critical Review on Polyphenols and Health Benefits of Black Soybeans, Nutrients, 9, 2017, p.103.

6.STEFANOVIC, O.D., TESIC, J.D., COMIC, L.R., Melilotus albus and Dorycnium herbaceum extracts as source of phenolic compounds and their antimicrobial, antibiofilm, and antioxidant potentials, J Food Drug Anal., 23, nr. 3, 2015, p. 417-424.

7.KAZANTZOGLOU, G., MAGIATIS, P., PANOUTSOPOULOS, G., et. al., Dorycnioside, a new phenylbutanone glucoside from Dorycnium pentaphyllum subsp. Herbaceum, Journal of Biosciences, 59, nr 1-2, 2004, p 23-26.

8.HANGANU D., VLASE L., Phytochemical Analysis of Isoflavons from some Fabaceae Species Extracts, Notulae Botanicae Hort Agrobotanici, 38, nr. 1, 2010, p. 57.

9.VARUT, R.M., ROTARU, L.T., GC-MS, HPLC, TLC of Dorycnium herbaceum Tincture Species and Synergistic / AntagonistEffect Testing in Combination with Antibiotics, Rev. Chim. (Bucharest), 68, no. 2, 2017, p. 228-231.

10.POPESCU F., POPESCU, R.M., BERBECARU-IOVAN, A., et. al., Evaluation of hypoglycemic and hypolipidemic effect of some vegetal extracts, using mice with streptozotocin - experimentally induced diabetes, Current Health Sciences J ournal, 40, nr. 2, 2014, p. 52-58.
11.CHU, E., CHEUNG, S.C., ROXANNA, A., Herbal Medicine,2nd edition oxidative Stress and Disease, Biomolecular and Clinical Aspects, 2011.

12.VARUT, RM, ROTARU, L.T., Determination of Polyphenol and Flavonoid Profiles and Testing the Antibacterial Effect of Acanthus longifolius Comparative with Vaccinium myrtillus, Rev. Chim.(Bucharest), 68, no. 7, 2017, p. 1419-1422.

13.ROTARU, L.T., ISTRATOAIE, O., UDRESCU, L., VARUT, R.M., TLC, GC-MS, HPLC Analyses and Testing the Antibacterial Effect of Tragopogon pratensis and Vaccinium myrtillus, Rev. Chim. (Bucharest), 69, no. 8, 2018, p. 1939-1943.

14.VARUT, R.M., GIRD, C.E., ROTARU, L.T., et al., Evaluation of Polyphenol and Flavonoid Profiles and the Antioxidant Effect of Carduus Acanthoides Hydroalcoholic Extract Compared with Vaccinium Myrtillus in an Animal Model of Diabetes Mellitus, Pharm Chem J, 51, nr. 12, 2018, p. 1088-1095, https://doi.org/10.1007/s11094018-1746-0.

15.LENZEN S., Diabetologia, 51, nr. 2, 2008, p. 216-226.

16.ROTARU, L.T., VARUT, R.M., COVEI, M.B., et. al., Determination of Antioxidant Components and Activity of Tamarix ramosissima Comparative with Vaccinium myrtillus on Streptozotocin-diabetic Mice, Rev. Chim.(Bucharest), 69, no. 7, p. 1860-1865.

17.QIN, Z., XIA, M., MA, J., et al, Am J Clin Nutrition, 90, 2009, p. 485492.

18.HELMSTADTER, A. SCHUSTER, N., Pharmazie, 65:315-321, 2010.

19.VEGA M.L., FERNANDEZ-MEJIA C., Oxidative Stress and Chronic Degenerative Diseases - A Role for Antioxidants, 9, 2013, p. 209-216. 20.ARULSELVAN, P., UMAMAHESWARI, A., FAKURAZI, S., Medicinal Plants as Antioxidant Agents: Understanding Their Mechanism of Action and Therapeutic, 11, 2012, p. 243-245.

21.KRISHNAMURTHY, P., WADHWANI, A., Antioxidant enzyme, 1, 2012, p. 12-13.

22.NAIR, S.P., SHAH, N.C, SHAH, R.M., Alteration in enzymatic antioxidant defense in diabetes mellitus, Biomedical Research, 23 (3):402-404, 2012.

23.TIWARI, B.K., PANDEY, K., ABIDI, A.B., Markers of Oxidative Stress during Diabetes Mellitus, Journal of Biomarkers, 2013.

Manuscript received: 19.07 .2018 